\title{
Probability of Nuclear Desalination for the Usage with Economical Incentives and Future Prospects
}

\author{
Ahmed Abdel Hamid Ahmed Abdallah \\ Department of Civil Engineering at the Giza Higher Institute of Engineering and Technology, Giza, Egypt
}

Email address:

dr.ahmedkt@gmail.com

\section{To cite this article:}

Ahmed Abdel Hamid Ahmed Abdallah. Probability of Nuclear Desalination for the Usage with Economical Incentives and Future Prospects. American Journal of Construction and Building Materials. Vol. 2, No. 1, 2018, pp. 1-9. doi: 10.11648/j.ajcbm.20180201.11

Received: April 6, 2018; Accepted: April 20, 2018; Published: May 19, 2018

\begin{abstract}
Considering the increasing demand for electricity, and the limited water resources in Egypt, adopting nuclear power plants as a dual purpose for producing electric power and fresh water has become urgent and essential. With the decision to use the nuclear power plants in Egypt, we introduce a technical demonstration for the different techniques and capabilities of NPPs that are used to supply the energy required to produce electricity fresh water by desalination. The current sources of energy which is required for the today's desalination methods costs much, beside its pollution effects. That motivated many countries to move towards the NPPs, which are cost competitive. In this paper, various desalination processes and the most appropriate method selected are assess and evaluated. Considering the limited fresh water resources in Egypt, different techniques used as heating sources for new desalination projects in the country, like solar systems and SMRs and their cost competitiveness have been reviewed and evaluated. The potential of adopting nuclear desalination in Egypt has been discussed and evaluated from technical and economical points of view, with the emphasis on the recent desalination capabilities. The desalination techniques were assessed according to the size, type of the nuclear reactor, electrical and thermal energy capacity, based on several technical and economical criteria. From this study, it could be inferred that, RO and MSF plants, as well as hybrid systems, are considered as energy intensive processes where energy cost is a major controlling parameter in the overall cost of desalination. Oil prices instability affect to a large extent, the cost of desalination significantly, whereas NPPs offer long term availability of fuel as well as long term fuel price stability. It has also low environmental impacts compared with other conventional desalination processes.
\end{abstract}

Keywords: Nuclear Desalination Plant, SAM Nuclear Power Reactors, Distillation Processes, Economical Analysis, Water Production Cost

\section{Introduction}

\subsection{General}

Egypt lies in a semi-arid to arid region where most of its renewable fresh water is transported by the Nile River from the Ethiopian and Equatorial plateau. Egypt's Nile water quota is almost the total water resources, which is about 55.5 billion $\mathrm{m} 3 / \mathrm{y}$. this amount constitutes about $90 \%$ of groundwater in the sandstone aquifer, but the cost of pumping and-conveyance are limiting factors. Coastal scattered winter rainfall contributes less than 1.5 billion $\mathrm{m} 3 / \mathrm{y}$ on average. The fast rate in population growth during the past few decades necessitates a corresponding growth in the water requirements. At present, the agricultural land per capita is less than $0.12 \mathrm{fed}$, ( $1 \mathrm{fed}=$ $4200 \mathrm{~m} 2$ ), and water is about $900 \mathrm{~m} 3 / \mathrm{y} /$ person. Pollution is another serious threat to water and land deterioration. It is anticipated that by the year 2025 water per capita will drop to about $600 \mathrm{~m} 3 / \mathrm{y}$, thus approaching the water poverty limit. The future strategy is based on a demand management approach, water savings and conservation projects, which, enforce public awareness programs, inhibit sources of water pollution, enhance the use of non-conventional water and in parallel promote strong cooperation with Nile countries to develop the upper Nile main catchment. However, the upper Nile development projects are long-term plans, while Egypt has to do more with a limited amount of fresh water. The immediate answer is to turn towards non-conventional sources such as water recycling, reuse of drainage water, treated industrial and 
sewage effluents, rainfall harvesting and conventional or nuclear desalination.

\subsection{Review of Desalination Techniques}

Desalination processes are categorized into two main types: processes using heat and process using electricity. The first type of processes are mainly the distillation processes, such as, multi-stage flash (MSF) or multi effect distillation (MED). Vapor compression (VC) is a distillation process but it uses electricity, just as the membrane based processes like the reverse osmosis (RO) and the electro- dialysis (ED). Of these, the most commonly used processes are MSF, MED and RO. $\mathrm{VC}$ is often combined with MED. In distillation processes, (MSF or MED) seawater is heated to evaporate pure vapor that is subsequently condensed. The heat energy required for distillation is usually supplied as low pressure saturated steam, which may be extracted from the exhaust of a back pressure turbine, from a crossover steam duct or from a dedicated, heat only plant. The amount and quality of steam, required to produce the desired amount of pure water, depends on the seawater temperature, the maximum brine temperature and the type, design and performance of the distillation plant. Usually, the efficiency of distillation plant is expressed in $\mathrm{kg}$ of pure water produced per $\mathrm{kg}$ of steam used in the first effect: this ratio is called the gain output ratio (GOR) $[1,4]$.

\subsubsection{Multi-stage Flash (MSF)}

Consider a vessel under vacuum, isolated from its environment and containing only seawater in equilibrium with its vapor at temperature $t$ and pressure $p$. When a heating fluid (generally hot water) at a temperature $t+\Delta t$ is introduced in the vessel, and if the pressure $\mathrm{p}$ is less than the saturation pressure, an instantaneous vaporization will be produced by a flash. The latent heat of vapor can then be transferred to cold seawater tubes passing through the vessel and the vapor condensed and recovered in the receptacle. Figure 1 shows schematically the principle of the MSF plant. The efficiency of the system can be considerably increased by having several stages in series (about 20 or more) for industrial production.

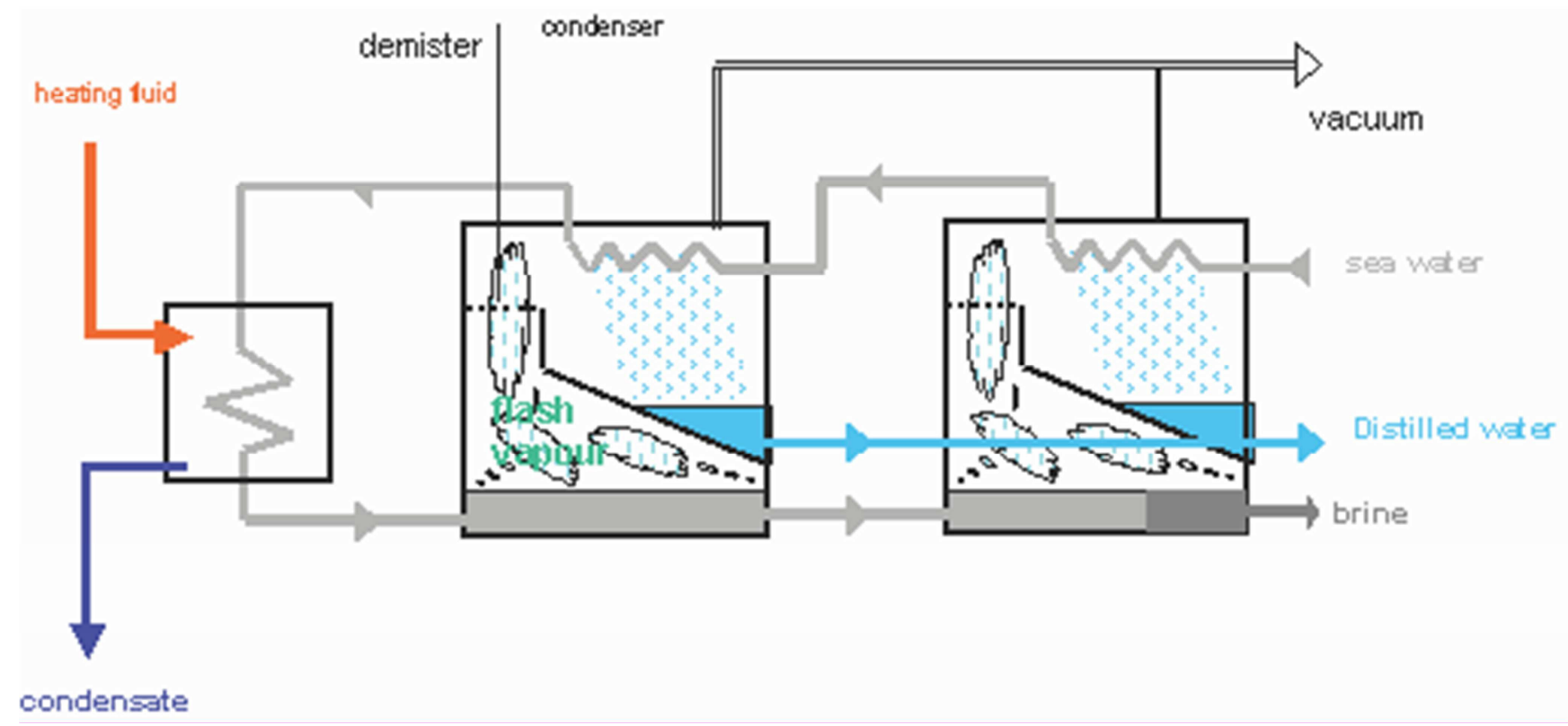

Figure 1. Schematic diagram of an industrial MSF system.

Seawater is first sent to a pre-treatment system where chemical additives or acids are added to avoid the formation of alkaline cruds or deposits on the tube surfaces. The water then passes through a de- aerator to reduce the quantity of oxygen and $\mathrm{CO} 2$ to minimize corrosion risks.

Incoming seawater, passing through successive stages in the opposite direction gets heated and is finally brought to a temperature of about 80 to $120^{\circ} \mathrm{C}$ in a "brine heater". It is then fed at the bottom of the first MSF stage where the initial flash takes place. It then passes into the next stages maintained at lower and lower pressures to ensure successive flashes in each stage. The condensate also passes from stage to stage and is collected in the distilled water reservoir.
MSF is particularly interesting where heat is easily available and one requires very large desalting capacity. This for example is the case in Saudi Arabia where about one million $\mathrm{m} 3$ /day is produced at Al-Jubail plant. The heat consumption of the MSF plant depends on the temperature of the heat source and on the GOR of the system but generally varies from 55 to $120 \mathrm{kWth} / \mathrm{m} 3$. Distilled water from MSF is of very high quality with the residual salinity of about $25 \mathrm{ppm}$.

Although $60 \%$ of the desalination plants in the world are of MSF type, the technology has reached its limits and is gradually being replaced by RO or MED plants which have a much higher potential for further development and which consume less energy. 


\subsubsection{Multi-effect Distillation (MED)}

Figure 2 shows the schematic flow diagram of a MED process, using horizontal tube evaporators (HTE). In each effect, heat is transferred from the condensing water vapor on one side of the tube bundles to the evaporating brine on the other side of the tubes.

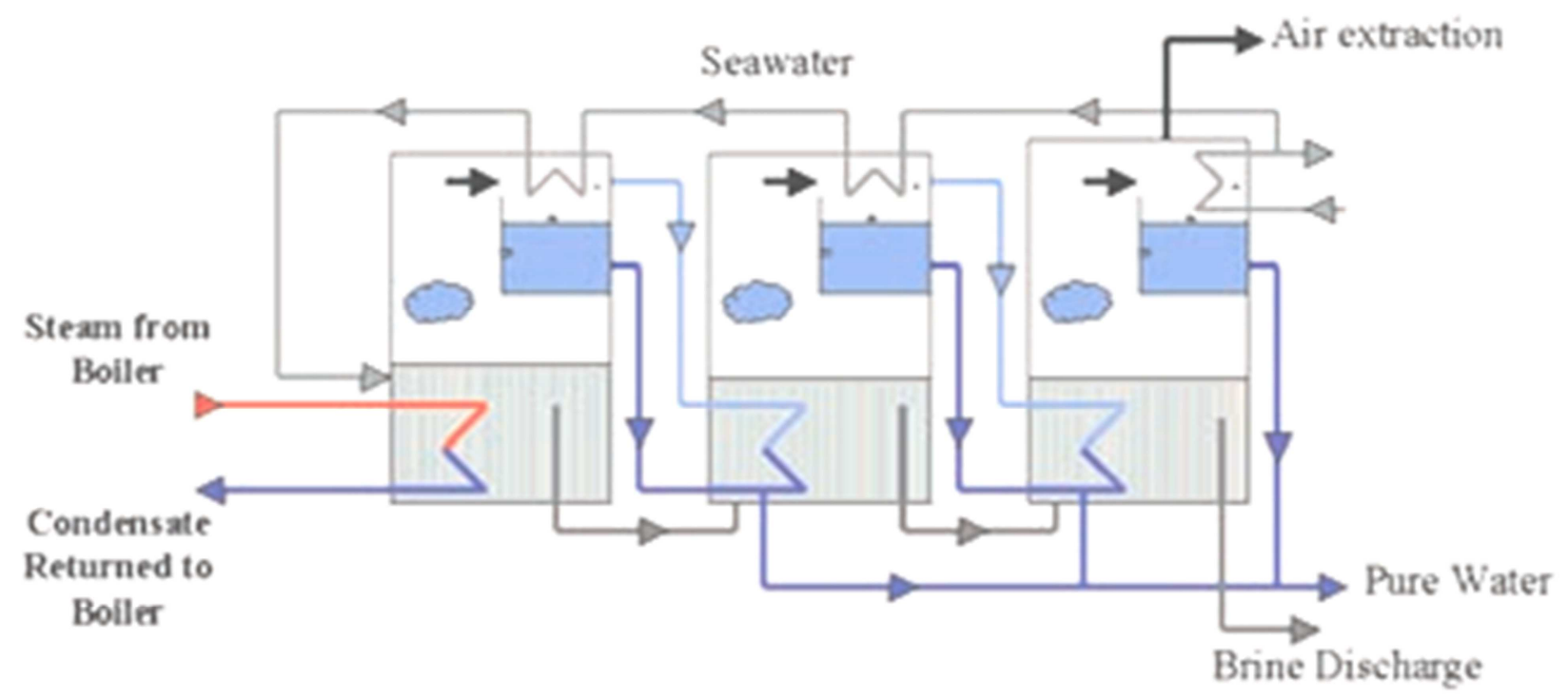

Figure 2. Schematic diagram of an MED system

This process is repeated successively in each of the effects at progressively lower pressure and temperature, driven by the water vapor from the preceding effect. In the last effect, at the lowest pressure and temperature, the water vapor condenses in the heat reject heat exchanger, which is cooled by incoming seawater. The condensate distillate is collected from each effect.

According to the direction of vapor and brine flow, there are "forward feed" and "backward feed" arrangements. In forward feed MED plants, vapor and brine move through the evaporators as parallel flows from the first high pressure evaporator to the last low pressure one. The pre-heating of feed water occurs in separate heat exchangers. In backward feed MED plants, vapor and brine move through the evaporators in opposite directions, whereby feed water pre-heating is eliminated.

Currently, MED processes with the highest technical and economic potential are the low temperature horizontal tube multi-effect process (LT-HTME) and the high temperature vertical tube evaporation process (HT-VTE). The main differences between LT-HTME plants and HT-VTE plants are in the arrangement of the evaporation tubes, the side of the tube where the evaporation takes place and the evaporation tube materials used. In LT-HTME plants, evaporating tubes are arranged horizontally and evaporation occurs by spraying the brine over the outer surface of the horizontal tubes creating a thin film from which steam evaporates. In HT-VTE plants, evaporation takes place inside vertical tubes.
Furthermore, in LT-HTME plants, the maximum brine temperature is limited to $70^{\circ} \mathrm{C}$, in order to avoid corrosion and scaling problems. Most LT-HTME plants now use low cost materials such as aluminum for heat exchanger and carbon steel as shell material.

\subsubsection{Reverse Osmosis}

Reverse osmosis (RO) is a natural process in which water molecules migrate across a semi-permeable membrane from a solution of low concentration (e.g. pure water) into a solution of higher concentration (e.g. seawater). RO is a separation process in which pure water is "forced" out of a concentrated saline solution by flowing through a membrane at a high static difference (Figure 2). This pressure difference must be higher than the osmotic pressure between the solution and the pure water. The saline feed is pumped into a closed vessel where it is pressurized against the membrane. As a portion of water passes through the membrane, the salt content in the remaining brine increases. At the same time, a portion of this brine is discharged without passing through the membrane. RO membranes are made in a variety of modular configurations: two of the commercially successful configurations are spiral-wound modules and hollow fibre modules. In both configurations, module elements are serially connected in pressure vessels, up to $7-8$ in the case of spiral wound and up to 2-3 in the case of hollow fiber modules. Figure 3 presents a schematic diagram of an industrial RO process. 


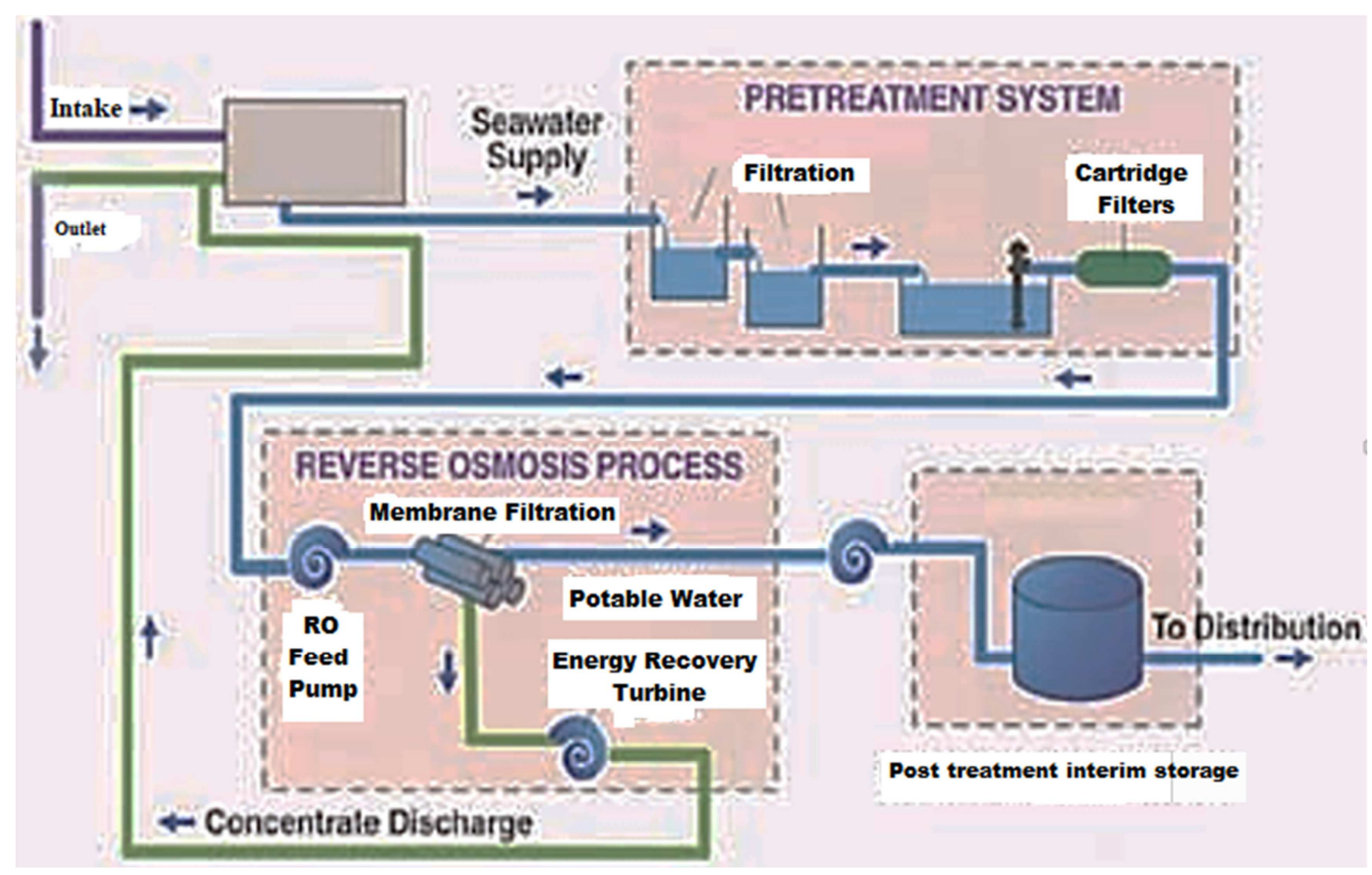

Figure 3. Schematic illustration of an operating RO plant.

\section{Current Egyptian Capabilities with Conventional Desalination}

The desalination experience in Egypt is relatively new compared to other countries especially in the Gulf States, but its importance began to grow recently as conventional water resources become fully exhausted. Where water is scarce in remote areas and deserts, small communities still practice primitive local techniques for harvesting and/or water mining. The real experience in desalination began in the mid-1970s when Ionics produced packaged ED plants and installed a number of them in remote areas, mainly for military and exploration camps industries, hotels and resorts. Due to vast urban expansion, mainly along the coastal areas, and the on-going developments in remote areas to relieve the population pressure from the old valley and delta, and to create new opportunities in new oil fields, water purification became competitive and safer than water transportation for very long distances. Although this is true in many applications, the public in Egypt, as elsewhere, has the idea that costs for desalting are never competitive. This has delayed the full realization of this alternative water supply, and research and development in this field. However, the private sector has introduced needs and the growing demand for domestic uses. This opened a market to the public sector, and some private companies are assembling or producing a wide range of RO units. Plants at military installations are now producing treatment and desalting units including a large capacity unit in Hurgada on the Red Sea, but the membrane know-how is still not available [5].

The Egyptian experience is rapidly building up in this field, but more efforts are needed to cope with the world trend to reduce the cost of desalination to a minimum. A remarkable effort has been made by the Energy and Environment Studies
Unit (EESU) at the Development Research and Technical Planning Center, Cairo University. Gas turbine exhaust is used for water desalination at the Suez Gulf Zone where there are about 125 turbine units working for power production and mechanical drive at the petroleum production companies Gupco, Suco and Petrobel. These gas turbine units are of a simple cycle design and have an installed capacity of about $600 \mathrm{MW}$. The exhaust temperature for these units ranges from 360 to $550^{\circ} \mathrm{C}$, which means that a tremendous amount of heat is wasted into the atmosphere. The Suez Gulf zone suffers from a severe shortage of potable water. Hence the study aims at evaluating the potential of utilizing heat from gas turbine exhaust for water desalination. The study adopted the multi-stage flash evaporator, (MSFE) method combined with a waste heat boiler working on gas turbine exhaust [6].

\section{Nuclear Desalination}

\subsection{Small and Medium Sized Reactors (SAMR) for Desalination}

Today, due to the high capital cost of large power reactors generating electricity via the steam cycle and the need to service small electricity grids under about $4 \mathrm{GWe}, \mathrm{b}$ there is a move to develop smaller units. These may be built independently or as modules in a larger complex, with capacity added incrementally as required (see section below on Modular construction using small reactor units). Economies of scale are provided by the numbers produced. There are also moves to develop small units for remote sites. Small units are seen as a much more manageable investment than big ones whose cost rivals the capitalization of the utilities concerned.

Generally, modern small reactors for power generation are 
expected to have greater simplicity of design, economy of mass production, and reduced siting costs. Most are also designed for a high level of passive or inherent safety in the event of malfunction. A 2010 report by a special committee convened by the American Nuclear Society showed that many safety provisions necessary, or at least prudent, in large reactors are not necessary in the small designs forthcoming. A 2009 assessment by the IAEA under its Innovative Nuclear Power Reactors \& Fuel Cycle (INPRO) program concluded that there could be 96 small modular reactors (SMRs) in operation around the world by 2030 in its 'high' case, and 43 units in the 'low' case, none of them in the USA. (In 2009 there were 133 small and medium units - up to about $700 \mathrm{MWe}$ in operation and 16 under construction, in 28 countries, totaling 60.3 GWe capacity. Table 1 . Depicts types of Medium and Small (25 MWe up) reactors with development well advanced, proposed for nuclear desalination in developing countries $[7,8]$.

\subsection{Comparative Economic Analysis}

Seawater desalination by $\mathrm{RO}$ has proved to be most economical as has been shown in the case studies from IAEA member States (Section 4). Apart from its need for an elaborate pre-treatment plant, RO has many advantages:

1) Enhanced flexibility due to modular structure.

2) Operation at ambient temperature, reducing corrosion risks.
3) Possibility of coupling with energy recovery devices, thus further reducing the costs.

4) High rate of development and considerable potential for further innovations as compared to the MSF technology, which has almost reached a saturation point in development.

Because of the particular advantages of MSF and RO technologies, it is logical to consider that a hybrid MSF-RO system may lead to greater cost reductions in water costs because:

1) Use of common, smaller seawater intake and outfall structures and other facilities.

2) Flexible and/or improved water quality by blending distillate from the MSF plant and the permeate from the RO plant.

3) Extension of the membrane life-times as a result of blending.

4) Enhanced flexibility of operation to meet various power and water ratios in case of a co- generation plant. Thus for example, one can operate the MSF plant during day time, when electricity demands are higher and the RO plant during night when electricity demands are lower and its cost are reduced.

5) Possibility of operation of the RO plant in the ROph mode through appropriate use of the MSF reject heat.

Table 1. Medium and small (25 MWe up) reactors with development well advanced [8].

\begin{tabular}{llll}
\hline Name & Capacity & Type & Developer \\
\hline KLT-40S & $35 \mathrm{MWe}$ & PWR & OKBM, Russia \\
VK-300 & $300 \mathrm{MWe}$ & BWR & Atomenergoproekt, Russia \\
CAREM & $27-100 \mathrm{MWe}$ & PWR & CNEA \& INVAP, Argentina \\
IRIS & $100-335 \mathrm{MWe}$ & PWR & Westinghouse-led, international \\
Westinghouse SMR & $200 \mathrm{MWe}$ & PWR & Westinghouse, USA \\
mPower & $150-180 \mathrm{MWe}$ & PWR & Babcock \& Wilcox + Bechtel, USA \\
SMR-160 & $160 \mathrm{MWe}$ & PWR & Holtec, USA \\
SMART & $100 \mathrm{MWe}$ & PWR & KAERI, South Korea \\
NuScale & $45 \mathrm{MWe}$ & PWR & NuScale Power + Fluor, USA \\
ACP100 & $100 \mathrm{MWe}$ & PWR & CNNC \& Guodian, China \\
HTR-PM & $2 \times 105 \mathrm{MWe}$ & HTR & INET \& Huaneng, China \\
EM2 & $240 \mathrm{MWe}$ & HTR & General Atomics (USA) \\
SC-HTGR (Antares) & $250 \mathrm{MWe}$ & HTR & Areva \\
BREST & $300 \mathrm{MWe}$ & FNR & RDIPE, Russia \\
SVBR-100 & $100 \mathrm{MWe}$ & FNR & AKME-engineering (Rosatom/En+), Russia \\
Gen4 module & $25 \mathrm{MWe}$ & FNR & Gen4 (Hyperion), USA \\
Prism & $311 \mathrm{MWe}$ & FNR & GE-Hitachi, USA \\
FUJI & $100 \mathrm{MWe}$ & MSR & ITHMSO, Japan-Russia-USA \\
\hline
\end{tabular}

The water costs from the Kalpakkam hybrid system are shown in Table 1. It can be noted that the cost of desalinated water depends on its quality. The product water quality from RO plant is about 350-500 ppm TDS and the water cost is US $\$ 0.95 / \mathrm{m} 3$. The desalinated water from MSF plant is of almost distilled quality (10 ppm TDS) and the water cost is higher (US \$ 1.18/m3). The water from hybrid system is of $125-175$ ppm quality and the water cost (US $\$ 1.10 / \mathrm{m} 3$ ) is in between RO and MSF. Hybrid system provides distilled quality water (10 ppm TDS) for the industries which require high quality, high value desalinated water for their process requirement and better quality water for drinking purpose[9, 10].

Table 2. Water costs of single and hybrid desalination techniques [10].

\begin{tabular}{llll}
\hline No. & $\begin{array}{l}\text { Type of desalination } \\
\text { process }\end{array}$ & $\begin{array}{l}\text { Product quality } \\
\text { (ppm) }\end{array}$ & $\begin{array}{l}\text { Water cost } \\
\text { (US \$ /m3) }\end{array}$ \\
\hline 1 & RO & $350-500$ & 0.95 \\
2 & MSF & 10 & 1.18 \\
3 & Hybrid (MSF \& RO) & $125-175$ & 1.10 \\
\hline
\end{tabular}

Figure 4, shows the variation of water costs with the energy costs. It is observed that the water cost from the RO plant is 
most sensitive to changes in energy costs.

Over a range of 0.3 to 2 for the power cost multiplier, the water cost from the MSF plant is highest, whereas the water cost from the two-stage RO plant is less than the corresponding costs from MSF and hybrid systems.

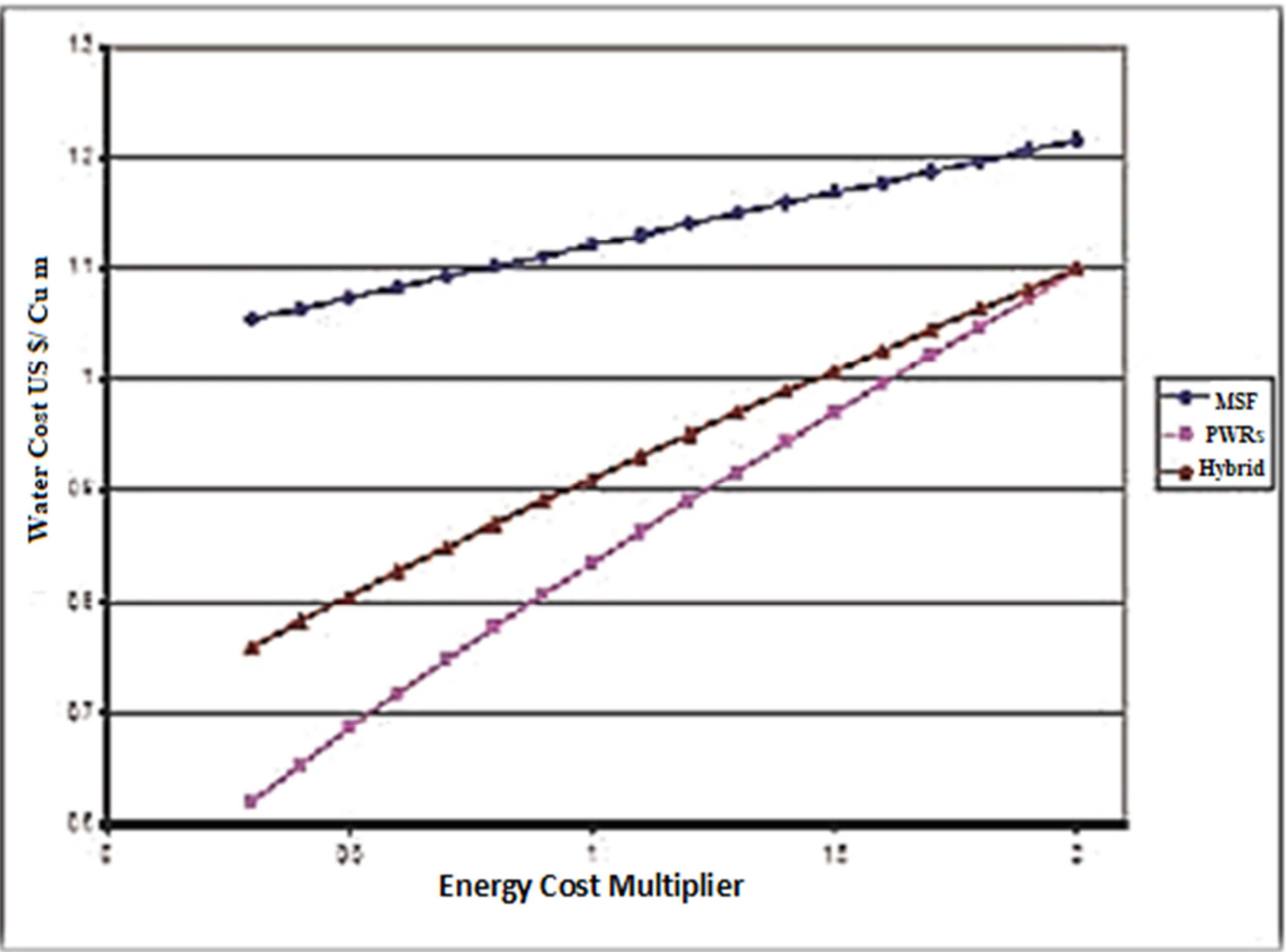

Figure 4. Variation of hybrid, RO and MSF water costs with the power cost [11].

\subsection{Results and Analysis of Some Case Studies}

Table 2 clearly shows that out of the eight reported studies, six are site specific and two are generic but representing potential sites. Similarly, the studies cover a large spectrum of operating or future reactor options, ranging from three
PWRs, two HWRs, two PBMRs, one dedicated, heat only reactor and one experimental reactor. These reactors have been coupled either to RO, ROph, MED, MED/VC or hybrid RO-MSF processes. These will be discussed one by one and according the desalination processes used.

Table 3. Summary of techno-economic site specific studies in some member states [13].

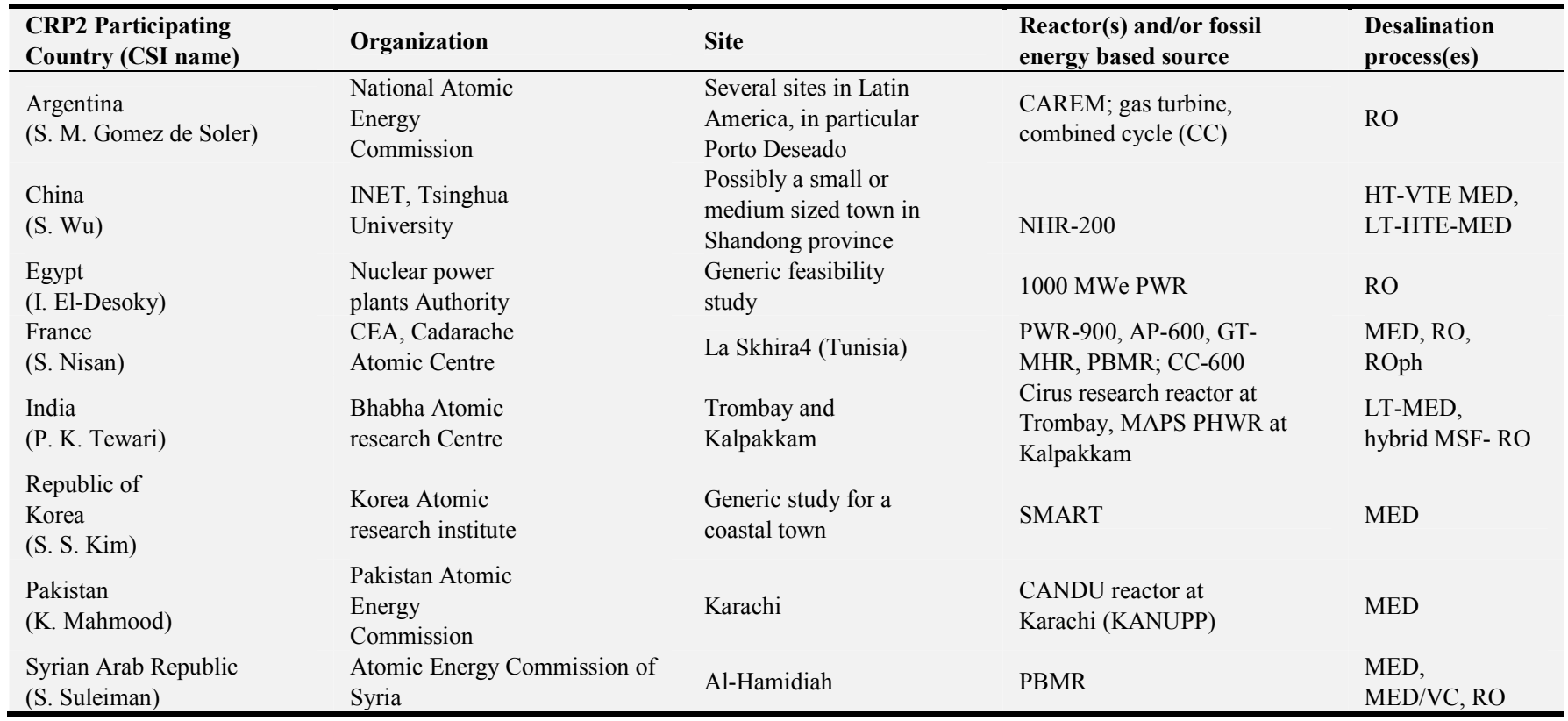


In these conditions, the water costs with the CAREM + RO and $\mathrm{CC}+\mathrm{RO}$ plants are respectively 0.68 and $0.7 \$ / \mathrm{m} 3$. Evidently, as the fossil fuel prices are greater than $20 \$ / \mathrm{bbl}$ (barrel), the costs with the CAREM option will be lower and lower.

Case Studies for a Nuclear Reactor Coupled To the RO Process

The first case is for a CAREM with RO for the Porto Deseado site in Argentina.

Three different capacities of the RO plant have been considered: $48000 \mathrm{~m} 3 /$ day (base case and two other cases, with 12000 and $24000 \mathrm{~m} 3 /$ day for sensitivity study. Power and water cost calculations have been made using the DEEP-3, (software for economical evaluation) model and the method used by the local Process Engineering Group for chemical plants evaluations (the IPEE method) [12].

The second case is for A $1000 \mathrm{MW}$ (e) PWR (pressurized water reactor) with $\mathrm{RO}$, (a case study for Egypt)

The assumptions for DEEP-3 calculations are given in Table 3:

Table 4. Assumptions used for the Egyptian case study.

\begin{tabular}{llll}
\hline Parameter & Units & RO plant & PWR1000 \\
\hline Net electrical power & MW(e) & & 951 \\
Plant efficiency & $\%$ & & 31 \\
Water plant nominal capacity & $\mathrm{m} 3 /$ day & 140000 & \\
Water plant specific base cost & $\$ / \mathrm{m} 3 /$ day & 800 & \\
Feed water temperature & ${ }^{\circ} \mathrm{C}$ & 23 & \\
Feed water salinity & $\mathrm{ppm}$ & 38500 & 60 \\
Plant life time & years & 30 & 60 \\
Construction lead time & months & 12 & 90 \\
Availability & $\%$ & 90 & \\
Average management salary & $\$ /$ year & 6000 & \\
Average labour salary & $\$ /$ year & 2400 & \\
Currency reference year & 1998 & & 0.045 \\
Interest/discount rate & $8 \%$ & & \\
Levelized energy cost & $\$ / \mathrm{kWh}$ & & \\
\hline
\end{tabular}

Plant efficiency $=$ electric $/$ thermal

Availability $=$ actual working days $/ 365$

Levelized energy cost $=$ average cost over the unit life time

Economic data for the $1000 \mathrm{MW}$ (e) PWR are taken from the MIT report [17]. Using this data in DEE leads to the power cost of $0.045 \$ / \mathrm{kW} . \mathrm{h}$ at $8 \%$ discount rate (decreasing). The corresponding desalination cost for a $140000 \mathrm{~m} 3 /$ day RO plant, coupled to the PWR, is estimated to be $0.65 \$ / \mathrm{m} 3$. The energy and water costs, with all these plants are compared in Table 4. The fossil fuel price for the CC-600 plant is 20.62 $\$ / \mathrm{bbl}$. The discount rate is $8 \%[14-16]$.

Table 5. Comparative cost of nuclear and fossil fueled RO desalination systems [17].

\begin{tabular}{|c|c|c|c|c|}
\hline & \multirow{2}{*}{ Units } & \multicolumn{3}{|c|}{ Nuclear desalination systems } \\
\hline & & PWR-900 + RO & AP-600 () + RO & $\mathrm{CC}-600+\mathrm{RO}$ \\
\hline Energy cost of the power plant & $\$ / \mathrm{kWh}$ & 0.0377 & 0.044 & 0.0496 \\
\hline Water cost & $\$ / \mathrm{m} 3$ & 0.611 & 0.632 & 0.885 \\
\hline
\end{tabular}

*AP = advanced PWR system

It can be observed that the desalination costs by the two nuclear options are respectively 31 and $29 \%$ lower than the corresponding cost by the CC-600 plant even in most favourable conditions (gas price of $20.62 \$ / \mathrm{bbl}$ or $150 \$ /$ toe).

What is (vapor compression, vc)

\section{Summary and Discussions}

The water production costs from a given nuclear (or fossil fuelled) desalination system are a complex function of several parameters, notably the power cost, the discount and interest rate, the water plant production capacity, the combined power and water plant availability and the water plant specific base cost.

As all these parameters have been specific to each study, it is difficult to arrive at general conclusions regarding a given power plant and desalination technology.

The range of values for different combinations could be summarized as follows [17]:

1) For the RO based systems, desalination costs vary from 0.6 to $0.94 \$ / \mathrm{m} 3$.

2) In all cases where the nuclear desalination costs are compared with those from the combined cycle plant + $\mathrm{RO}$, it is observed that the nuclear desalination costs are much lower.

3) For the MED based systems, the nuclear desalination costs vary from 0.7 to $0.96 \$ / \mathrm{m} 3$.

4) In one study, the MED/VC, coupled to a PWR leads to a cost of $0.5 \$ / \mathrm{m}^{3}$.

5) As in the case of RO, wherever comparisons have been made, the desalination cost

6) of nuclear reactors coupled to MED are systematically 
more than $20 \%$ lower than the

7) Corresponding cost by the combined cycle + MED systems.

8) In a hybrid MSF-RO system, the desalination cost of MSF, coupled to a PHWR is $1.18 \$ / \mathrm{m} 3$, compared to $0.95 \$ / \mathrm{m} 3$ for RO but that of the hybrid MSF-RO system is $1.1 \$ / \mathrm{m} 3$. The cost will be further reduced when hybrid system capacity is increased.

9) With identical economic hypotheses, used for three cases, DEEP-3 results show that nuclear reactors, coupled to RO would lead to a desalination cost of 0.6 to $0.74 \$ / \mathrm{m} 3$. Corresponding cost for MED would be about $0.88 \$ / \mathrm{m} 3$.

10) Furthermore, sensitivity calculations performed in the context of above studies can also lead to certain conclusions. Thus for example, for an MED plant coupled to a PHWR (Pakistan study), a $\pm 30 \%$ variation in discount rate leads to a variation of about $16 \%$ in the water cost. However, a $30 \%$ variation in total plant production capacity leads to a reduction of only $0.3 \%$ in water cost. By increasing the total water plant availability by $30 \%$, the water cost reduces to $18 \%$. Water cost increases by the same amount when water plant base cost is increased by $30 \%$. Further harmonization in the case studies was made possible by the availability of DEEP-3 files from three studies (Argentina, Egypt and France).

Table 6. Results of some case studies [17]. Water cost in $\$ / \mathrm{m}^{3}$

The results, summarized in Table 5, depicts that:

1) $\mathrm{PWR}+\mathrm{RO}$ costs vary from 0.611 to $0.738 \mathrm{\$} / \mathrm{m} 3$, depending upon the power costs of the PWR.

2) At least in two cases, the PWR + MED costs are nearly the same, about $0.88 \$ / \mathrm{m} 3$.

3) Under these conditions, desalted water cost from RO is from 16 to $31 \%$ lower than MED plant.

\section{Conclusions}

It appears that in Egypt, based on current prices charged for water, desalination is currently only competitive with traditional water sources in remote locations. However, with the decision to introduce nuclear power plants, there is a technical demonstration for the use of NPPs for supply of electricity and producing fresh water by desalination. Today, current desalination methods require large amounts of energy which is costly both in environmental pollution and in money terms. However, the cost competitiveness of nuclear desalination, the type of desalination technique and the size and type of the nuclear reactor have to be assessed and evaluated based on several technical and economic criteria. RO and MSF plants, as well as hybrid systems, are considered as energy intensive processes where energy cost is a major controlling parameter in the overall cost of desalination. Oil prices instability affect to a large extent, the cost of desalination significantly, whereas NPPs offer long term availability of fuel as well as long term fuel price stability. It has also low environmental impacts compared with other conventional desalination processes. In this paper, various desalination processes and most appropriate method selected are reviewed. The recent desalination capabilities in Egypt have been reviewed and discussed in the light of the limited water resources in the country. Different techniques used as heating sources for new desalination projects in Egypt like solar systems and SMRs and their cost competitiveness have been reviewed and evaluated. The potential of adopting nuclear desalination in Egypt has been discussed and evaluated from technical and economic point of view.

\section{References}

[1] INTERNATIONAL ATOMIC ENERGY AGENCY, Environmental Impact Assessment of Nuclear Desalination, IAEATECDOC- 1642, (2016), IAEA, Vienna

[2] AMTA, Water Desalination Processes, American Authority in Membrane Technology, FS-8, Feb. (2017).

[3] World Water Vision Commission Report: A Water Secure World, World Water Forum, The Hague, Netherlands, (2015).

[4] IAEA, Status of Non-Electric Nuclear Heat Applications: Technology and Safety, IAEA-TECDOC-1184, Vienna (2016).

[5] IAEA, "Experience gained in the operation and maintenance of the nuclear desalination plant in Aktau, Kazakhstan", Nuclear Desalination of Sea Water (Proc. Conf. Taejon, 1997), IAEA, Vienna (2017).

[6] INTERNATIONAL ATOMIC ENERGY AGENCY, Introduction of Nuclear Desalination: A Guidebook, Technical Reports Series No. 400, IAEA, Vienna (2015).

[7] INTERNATIONAL ATOMIC ENERGY AGENCY, Guidance for Preparing User Requirements Documents for Small and Medium Reactors and their Application, IAEATECDOC- 1167, Vienna (2000).

[8] INTERNATIONAL ATOMIC ENERGY AGENCY, Safety Aspects of Nuclear Plants Coupled with Seawater Desalination and/or Other Heat Utilization Units (in press).

[9] Examining the Economics of Seawater Desalination Using the DEEP Code, IAEATECDOC- 1186, IAEA, Vienna (2017).

[10] WANGNICK, K., Present status of thermal seawater desalination techniques, IDA Journal 10/1.

[11] INTERNATIONAL ATOMIC ENERGY AGENCY, Use of Nuclear Reactors for Seawater Desalination, IAEA-TECDOC-574, Vienna (2016).

[12] INTERNATIONAL ATOMIC ENERGY AGENCY, Technical and Economic Evaluation of Potable Water Production through Desalination of Seawater by Using Nuclear Energy and Other Means, IAEA-TECDOC- 666, Vienna (2017).

[13] INTERNATIONAL ATOMIC ENERGY AGENCY, Nuclear Desalination of Sea Water (Proc. Conf. Taejon, 1997), IAEA, Vienna (2016).

[14] DOVAL, A., MASRIERA, N., "Analysis of desalination system models relevant for the safety evaluation of a nuclear desalination plant", IDA World Congress on Desalination and Water Reuse, San Diego, California, September, (2015). 
[15] CHANG, M. H., SIM, S. K., HWANG, Y. D., SMART-An Advanced Small integral PWR for Nuclear Desalination and Power Generation, Global '99 - International Conference on Future Nuclear Systems, Jackson Hole, Wyoming, (2016).

[16] BAE, K. H., KIM, H. C., CHANG, M. H., SIM, S. K., Safety Evaluation of the Inherent and Passive Safety Features of the SMART Design, Annals of Nuclear Energy 2 (2017) 333-349.
[17] CHANG, H. J. YEO, W., Advanced Design Features Adopted in SMART, IAEA-SR- 218/28, International Seminar on Status and Prospects for Small and Medium Size Reactors, Cairo, Egypt, 2015, IAEA, Vienna (2016). 